\title{
The Effects of Psychological Well-Being and Academic Efficacy on the Self-Leadership of Nursing Students
}

\author{
Kwon Jin-hee ${ }^{1}$ and Choi Bong-sil ${ }^{2}$ \\ Department of Nursing, Nambu University, 23 Chumdan Jungang-ro, Gwangsan-gu, \\ Gwangju, Korea \\ Ignygny7007@hanmail.net, 2choibs@nambu.ac.kr
}

\begin{abstract}
The purpose of this study was to investigate the factors that psychological well-being and academic self-efficacy of nursing students affect self-leadership. This is a descriptive study that collected data through a structured questionnaire for first-year students at a nursing college in Korea. The data were analyzed by descriptive statistics and Pearson correlation. The scores for psychological well-being, academic self-efficacy, and self-leadership were $3.25,3.00$, and 3.43, respectively. The psychological well-being and self-leadership $(r=.088$, $p<.001)$, academic self-efficacy and self-leadership $(r=.105, p<.001)$, and psychological well-being and academic self-efficacy $(r=.142, p<.001)$ all showed significant correlations. We expect this study to be used as basic data for developing curriculums and programs to foster professional nurses by enhancing the self-leadership of nursing students, which affects their self-competence and motivation.
\end{abstract}

Keywords: Nursing students, Psychological well-being, Academic efficacy, Self-leadership

\section{Introduction}

\subsection{Background}

Nursing students concentrate on their college life to pass the national exam to become professional nurses by learning theories and skills to develop their competency according to their corresponding curriculums [1].

However, in the process of adjusting to university life, nursing students are exposed to various stressful situations such as excessive academic burden, interpersonal relationships with peers, exams, and employment. In addition to acquiring professional knowledge about majors, they experience social roles much too early due to clinical practice and this acts as an obstacle in adjusting to college life [2]. Nursing students are also exposed to a variety of stresses, such as difficulties in applying theoretical nursing knowledge to clinical practice while adjusting to unfamiliar clinical settings, role ambiguity, heavy workloads, helplessness, lack of ability, uncertainty, emotional distress in interpersonal relationships with patients and family members, lack of control in unexpected situations, and difficulties in forming relationships with advisors and colleagues.

Nursing students value self-leadership as a concept to adjust to university life, overcome problems, and develop capabilities to cope with clinical settings. Self-leadership is a process

Article History:

Received (November 13, 2019), Review Result (December 20, 2019), Accepted (January 25, 2020) 
of exerting the influence necessary to perform tasks and is presented as a core competency that should be formed during university life to develop self-management and internal motivation that emphasizes autonomy and responsibility for setting goals and self-control [3]. Previous studies have reported that greater self-leadership increases autonomy and passion [4] and that higher academic major satisfaction has positive effects on the progress toward achieving goals and helps to improve nursing capabilities [5].

According to a prior study on nursing students, self-leadership was found to be correlated with psychological well-being [6] and academic self-efficacy [7]. Ryff considered the 6 factors of self-acceptance, personal growth, purpose in life, positive relations with others, environmental mastery, and autonomy as the key elements of psychological well-being. She reported that a high level of psychological well-being will lead individuals to continuously explore positive attitudes, potential, and talents, find meaning and goals in their experiences, handle the environment to fit their relationships and desires and act on their beliefs [8]. Meanwhile, academic self-efficacy refers to the judgment that learners make about their ability to organize and implement the actions required to perform tasks related to their learning situation [9] and has a significant impact on performance or goal setting [10]. Academic self-efficacy is considered to be deeply related to self-management for achieving one's task or the self-leadership of the self-control system. Namely, it is a cognitive system that tries to successfully perform given learning tasks according to one's expectations or goals [11]. Nursing professionals also require self-leadership that emphasizes creativity and imagination to improve their work performance and enhance organizational effectiveness as they adapt to new changes [12]. Self-leadership has also been identified among students as an important variable to adapt to nursing college, but studies verifying its effects are insufficient [13]. Therefore, we need to make efforts to cultivate leadership in the curriculums of nursing colleges to develop core competencies required in clinical settings and for students to grow into professional nurses [14].

Therefore, this study attempted to analyze the influence factors on self-leadership to grow into professional nurses by raising self-leadership and internal motivation and preparing basic data for curriculum and program development to improve it.

\subsection{Purpose}

The purpose of this study is to examine the effects of psychological well-being and academic self-efficacy on the self-leadership of nursing students. The details are as follows.

* Identify the general characteristics.

* Identify the degree of psychological well-being, academic self-efficacy, and selfleadership.

* Identify the correlation between psychological well-being, academic self-efficacy, and self-leadership.

\section{Method}

\subsection{Design}

This is a descriptive study to examine the degree of psychological well-being, academic self-efficacy, and self-leadership of nursing students and to identify the factors that influence self-leadership. 


\subsection{Participants}

The participants of this study were nursing students attending a nursing college in Korea and we collected data through a survey. Since the variables may vary depending on the academic year, this study was performed on first-year students before they began their major studies and clinical practice. A total of 203 data points, excluding insufficient responses, were used for the final analysis among 210 students who understood the purpose of this study and agreed to participate in the survey. The G*Power 3.1 program was used to confirm the adequacy of the sample size. In terms of regression analysis, the minimum number of samples required was calculated to be 162 for a moderate effect of .15 , a significance level of $5 \%$, a power of $90 \%$, and 13 predictors. This study satisfied the analysis conditions.

\subsection{Research tools}

\subsubsection{Psychological Well-being}

For psychological well-being, we used a modified and revised Korean version of the Psychological Well-Being (PWB) Scale by Kim et al. [15] which was originally developed by Ryff et al. (1995). On a 5-point Likert scale, higher scores indicate higher psychological wellbeing. The reliability of the tool was Cronbach's $\alpha=.90$ at the time of development and Cronbach's $\alpha=.92$ in this study.

\subsubsection{Academic self-efficacy}

For academic self-efficacy, we used the tool developed by Kim and Park [9]. On a 5-point Likert scale, higher scores indicate higher academic self-efficacy. In terms of reliability, Cronbach's $\alpha$ was .74 for confidence, .76 for self-regulated efficacy, and .84 for task difficulty in the study by Kim and Park [9]. In this study, Cronbach's $\alpha$ was .81 for confidence, .81 for self-regulated efficacy, .74 for task difficulty, and the overall Cronbach's $\alpha$ was .84 .

\subsubsection{Self-leadership}

For self-leadership, we used the tool revised and modified by Shin [16] based on the Revised Self-Leadership Questionnaire (RSLQ) originally developed by Houghton and Neck (2002). On a 5-point Likert scale, higher scores indicate higher self-leadership. The reliability of the tool was Cronbach's $\alpha=.87$ in the study by Shin [16], and Cronbach's $\alpha=.92$ in this study.

\subsection{Data analysis method}

In this study, we used SPSS WIN 22.0 to analyze the collected data. We obtained the frequency and percentage for general characteristics and the mean and standard deviation for psychological well-being, academic self-efficacy, and self-leadership. The relationship between psychological well-being, academic self-efficacy, and self-leadership was analyzed by Pearson's correlation coefficients. 


\section{Results}

\subsection{General characteristics}

[Table 1] shows the general characteristics of this study. In terms of age, $58.6 \%$ of the participants were under 20 years old, $29.6 \%$ were $21 \sim 25$ years old, $6.4 \%$ were over 31 years old, and $5.4 \%$ were $26 \sim 30$ years old. Of the total participants, $27.1 \%$ were men and $72.9 \%$ were women. In terms of religion, $41.4 \%$ of the participants were religious while $58.6 \%$ had no religion, and $10.3 \%, 73.9 \%$, and $15.8 \%$ of the participants considered their economic status as low, average, and high, respectively. In terms of residence status, $38.9 \%$ lived alone, $34.5 \%$ lived with their parents, $17.7 \%$ in a dormitory, and $8.9 \%$ in other types of residences. The level of satisfaction with friendship was in the order of high $(39.9 \%)$, average $(34.5 \%)$, very high $(17.2 \%)$, low $(6.4 \%)$, and very low (2.0\%). As for involvement in club activities, $30.5 \%$ answered yes and $69.5 \%$ answered no, $12.3 \%$ of the participants had leadership experience and $87.7 \%$ had no leadership experience. In terms of assessing their leadership competency, $61.1 \%$ answered average, $21.7 \%$ low, $9.9 \%$ high, and $3.9 \%$ very low. The level of satisfaction with college life was in the order of average (49.8\%), high (22.7\%), low $(18.2 \%)$, very low $(5.9 \%)$, and very high $(3.4 \%)$.

Table 1. General characteristics of subjects. $(\mathrm{N}=203)$

\begin{tabular}{|c|c|c|c|c|}
\hline Variable & Categories & $\mathrm{n}$ & $\%$ & 누적 퍼센트 \\
\hline \multirow{4}{*}{ Age } & Under 20 & 119 & 58.6 & 58.6 \\
\hline & $21 \sim 25$ & 60 & 29.6 & 88.2 \\
\hline & $26 \sim 30$ & 11 & 5.4 & 93.6 \\
\hline & Over 31 & 13 & 6.4 & 100.0 \\
\hline \multirow{2}{*}{ Gender } & Male & 55 & 27.1 & 27.1 \\
\hline & Female & 148 & 72.9 & 100.0 \\
\hline \multirow[t]{2}{*}{ Religion } & Yes & 84 & 41.4 & 41.4 \\
\hline & No & 119 & 58.6 & 100.0 \\
\hline \multirow{3}{*}{$\begin{array}{c}\text { Economic } \\
\text { Status }\end{array}$} & Low & 21 & 10.3 & 10.3 \\
\hline & Middle & 150 & 73.9 & 84.2 \\
\hline & High & 32 & 15.8 & 100.0 \\
\hline \multirow{4}{*}{$\begin{array}{l}\text { Residence } \\
\text { Status }\end{array}$} & Parents & 70 & 34.5 & 34.5 \\
\hline & Dormitory & 36 & 17.7 & 52.2 \\
\hline & Live alone & 79 & 38.9 & 91.1 \\
\hline & etcetera & 18 & 8.9 & 100.0 \\
\hline \multirow{5}{*}{$\begin{array}{l}\text { Satisfaction } \\
\text { of friendship }\end{array}$} & Very Low & 4 & 2.0 & 2.0 \\
\hline & Low & 13 & 6.4 & 8.4 \\
\hline & Middle & 70 & 34.5 & 42.9 \\
\hline & High & 81 & 39.9 & 82.8 \\
\hline & Very High & 35 & 17.2 & 100.0 \\
\hline \multirow{2}{*}{$\begin{array}{l}\text { Group } \\
\text { activity }\end{array}$} & Yes & 62 & 30.5 & 30.5 \\
\hline & No & 141 & 69.5 & 100.0 \\
\hline Leadership & Yes & 25 & 12.3 & 12.3 \\
\hline
\end{tabular}




\begin{tabular}{|c|c|c|c|c|}
\hline experiences & No & 178 & 87.7 & 100.0 \\
\hline \multirow{4}{*}{$\begin{array}{c}\text { Leadership } \\
\text { competency }\end{array}$} & Very Low & 8 & 3.9 & 3.9 \\
\cline { 2 - 5 } & Low & 44 & 21.7 & 25.6 \\
\cline { 2 - 5 } & Middle & 124 & 61.1 & 86.7 \\
\cline { 2 - 5 } & High & 20 & 9.9 & 96.6 \\
\hline \multirow{4}{*}{$\begin{array}{c}\text { Satisfaction } \\
\text { with } \\
\text { College life }\end{array}$} & Very High & 7 & 3.4 & 5.9 \\
\cline { 2 - 5 } & Very Low & 12 & 5.9 & 24.1 \\
\cline { 2 - 5 } & Low & 37 & 18.2 & 73.9 \\
\cline { 2 - 5 } & Middle & 101 & 49.8 & 96.6 \\
\hline
\end{tabular}

\subsection{Degree of psychological well-being, academic self-efficacy, and self-leadership}

[Table 2] shows the degree of the participants' psychological well-being, academic selfefficacy, and self-leadership. The scores for psychological well-being, academic self-efficacy, and self-leadership were $3.25 \pm 0.47,3.00 \pm 0.47$, and $3.43 \pm 0.51$, respectively.

Table 2. Degree of psychological well-being, academic self-efficiency, and self-leadership. (N=203)

\begin{tabular}{|c|c|c|c|c|}
\hline & $\mathrm{M} \pm \mathrm{SD}$ & Min & Max & Range \\
\hline Psychological well-being & $3.25 \pm 0.47$ & 1.98 & 4.8 & $1 \sim 5$ \\
\hline Academic self-efficacy & $3.00 \pm 0.47$ & 1.82 & 4.71 & $1 \sim 5$ \\
\hline Self-leadership & $3.43 \pm 0.51$ & 1.71 & 5 & $1 \sim 5$ \\
\hline
\end{tabular}

\subsection{Correlation between the psychological well-being, academic self-efficacy, and self- leadership}

[Table 3] shows the correlation between the participants' psychological well-being, academic self-efficacy, and self-leadership. The psychological well-being and self-leadership $(\mathrm{r}=.088, \mathrm{p}<.001)$, academic self-efficacy and self-leadership $(\mathrm{r}=.105, \mathrm{p}<.001)$, and psychological well-being and academic self-efficacy $(r=.142, p<.001)$ all showed significant correlations.

Table 3. Correlations among psychological well-being, academic self-efficiency, and self-leadership

$(\mathrm{N}=203)$

\begin{tabular}{|c|c|c|c|}
\hline Variable & Psychological well-being & Academic self-efficacy & Self-Leadership \\
\hline Psychological well-being & 1 & - & - \\
\hline Academic self-efficacy & $\begin{array}{c}.142 \\
(\mathrm{p}<.001)\end{array}$ & 1 & 1 \\
\hline Self-leadership & $\begin{array}{c}.088 \\
(\mathrm{p}<.001)\end{array}$ & $\begin{array}{c}.105 \\
(\mathrm{p}<.001)\end{array}$ & 1 \\
\hline
\end{tabular}




\section{Discussion}

The purpose of this study was to examine the psychological well-being, academic selfefficacy, and self-leadership of nursing students and identify the effects on self-leadership to prepare basic data to develop curriculums and programs to enhance self-leadership.

The mean score for self-leadership of the nursing students in this study was 3.43 , which is higher than the median. This is lower than the score of 3.72 from a study on second and thirdyear students in 3-year colleges and third- and fourth-year students in 4-year colleges who experience at least 1 semester of clinical practice [17]. It is also lower than the score of 3.70 from a study on third-year students in 3-year colleges and fourth-year students in 4-year colleges [18]. The mean score for psychological well-being was 3.26, which is higher than the median. This is higher than the score of 149.6 (range: 46 276, 2.72 when converted to a 5point scale) from a study on all grades of nursing students using a 6-point Likert scale with the same tool [6], and higher than the score of 3.33 for first-year students (2.78 when converted to a 5-point scale) from a study on general university

Students [19].

The mean score for academic self-efficacy was 3.00, which is higher than the median. This is similar to the score of 3.09 from a prior study on first- and fourth-year nursing students using the same tool [20], but lower than the score of 3.81 from the study by Han on first-year nursing students [10].

There was a positive correlation between psychological well-being and self-leadership $(\mathrm{r}=.088, \mathrm{p}<.001)$, and the most influential factor on the self-leadership of nursing students was psychological well-being $(\beta=.25, \mathrm{p}<=.005)$. This is similar to the results of prior studies [21][22][23] on the relationship between psychological well-being and self-leadership. This shows that people who have a specific growth and life purpose to overcome new challenges and difficulties are motivated to lead a positive life [23]. The psychological well-being of students includes the quality of their lives, their satisfaction and happiness with school life, and how well they function as members of the school [21]. A positive correlation was found between self-leadership and academic self-efficacy $(r=.105, p<.001)$. This is consistent with the results of prior studies on nursing students [23][24]. A study by Lee also suggested that college students with high academic self-efficacy were strong in their beliefs and wanted to achieve more [25]. Academic self-efficacy is considered to be deeply related to selfmanagement for achieving one's task or the self-leadership of the self-control system because it is a cognitive system that tries to successfully perform the given learning task according to one's expectations or goals [11]. This can be viewed as the process in which nursing students set their own goals, motivate themselves, and strive to achieve results. Guidance will be required to enhance this process [7].

The results of this study confirm that the psychological well-being of nursing students is a factor that affects their academic performance. To enhance self-leadership, interventions will be required.

\section{Conclusion}

The purpose of this study was to examine the effects of psychological well-being and academic self-efficacy on the self-leadership of nursing students and to prepare basic data to develop curriculums and programs to enhance self-leadership. The psychological well-being, academic self-efficacy, and self-leadership of the participants were above average, and there was a significant correlation between psychological well-being, academic self-efficacy, and self-leadership. 
Based on the results of this study, we propose the following.

First, it is necessary to develop curriculums and programs that can enhance psychological well-being and self-leadership considering the characteristics of nursing students and verify the effectiveness of the improved curriculums and programs.

Second, follow-up studies will be required because there is a lack of research on verifying the relationship between psychological well-being, academic self-efficacy, and self-leadership of nursing students.

Third, as this study was limited to nursing students at one university, additional studies need to be carried out by expanding the regional scope and participants to generalize the results.

\section{References}

[1] J. Liaschenko, E. Peter, "Nursing ethics and conceptualizations of nursing: Profession practice and work," Journal of Advance Nursing, vol.46, no.5, pp.488-495, (2010)

[2] H. J. Park and I. S. Jang, "Stress, depression, coping styles and satisfaction of clinical practice in nursing students," The Journal of Korean Academic Society of Nursing Education, vol.16, no.1, pp.14-23, (2010)

[3] E. S. Lee and E. J. Bong, "The effects of self-leadership, academic self-efficacy, and instructor-student interaction on self-directed learning in nursing students," Journal of East-West Nursing Research, vol.23, no.2, pp.107-114, (2017)

[4] C. C. Manz, "Mastering self-leadership; empowering yourself for personal excellence," Englewood Cliffs, New Jersey; Prentice Hall

[5] M. A. Park, "Self-leadership, stress on clinical practice, and stress coping styles in nursing students," Unpublished Master's Thesis, Kyungpook Nation University, (2014)

[6] J. I. Kim, "The effects of emotional intelligence, self-leadership, psychological well-being to academic achievement of the nursing college student," Journal of the Korea Academia-Industrial Cooperation Society, vol.19, no.1, pp.574-583, (2018)

[7] J. Y Choi, "Study on factors affecting self-leadership of nursing students," Unpublished doctoral dissertation, Eulji University, (2016)

[8] Ryff, CD. Keyes and C. L. M, "The structure of psychological well-being revisited," Journal of Personality and Social Psychology, vol.73, pp.549-559

[9] A. Y. Kim and I. Y. Park, "Development and validation of academic self-efficacy," Korean Journal of educational research, vol.39, no.1, pp.95-123, (2001)

[10] S. J. Han, "The influence of academic self-efficacy and major satisfaction," Academic Society of Adult Nursing, vol.25, no.5, pp.559-566, (2013)

[11] M. K. Kim, "The relationship of the revised self-leadership questionnaire and self-efficacy in college students," The Korean Journal of Korea HDR Research, vol.7, no.3. pp.21-43., (2012)

[12] H. J. Won and S. H. Cho, "A Review of research on self-leadership in nurses," J Korean Acad Nurs Adm, vol.19, no.3, pp.382-393, (2013)

[13] M. S. Kim, "The influence of self-leadership and critical thinking disposition on college adaptation among nursing students," J Korean Acad Soc Nurs Educ, vol.23, no.2, pp.184-193, (2017)

[14] D. Y. Lee and J. H. Cho, "Convergence influence of self-resilience, critical thinking, and academic selfefficacy on self-leadership of nursing students," Journal of the Korea Convergence Society, vol.9, no.10, pp.561-569, (2018)

[15] M. S. Kim, H. W. Kim, and G. H. Cha, "Analyses on the construct of psychological wellbeing(PWB) of Korean male and female adults," Korean Psychology Association, vol.15, no.2, pp.19-39, (2001) 
The Effects of Psychological Well-Being and Academic Efficacy on the Self-Leadership of Nursing Students

[16] M. G. Shin, M.S. Kim, and Y S. Han, "A study on the validation of the Korean version of the revised selfleadership questionnaire (RSLQ) for Korean college students," The Korean Journal of School Psychology, vol.6, no.3, pp.313-340, (2009)

[17] N. Y. Yang and S. Y. Moon, "Relationship of self-leadership, stress, and satisfaction in clinical practice of nursing students," The Journal of Korean Nursing Administration Academic Society, vol.17, no.2, pp.216$225,(\mathbf{2 0 1 1})$

[18] B. M. Seo, "Factors affecting clinical competence among nursing students," Unpublished Doctoral Dissertation, Inje University, (2014)

[19] Y, M. Cha, "The effects of life stress and psychological well-being on the adjustment to college life," Master's Thesis, Donga University, (2017)

[20] O. S. Lee, "The relationship between emotional intelligence, academic self-efficacy, and self-leadership among nursing," Journal of the Korea Academia-industrial Cooperation Society, vol.16, no.9, pp.6036-6043, (2015)

[21] J. S. Moon, "Relationship of mindfulness and psychological well-being: Structural equation and Q type analysis focused on mediative effects of imagination awareness and cognitive defusion," Unpublished Doctoral Dissertation, Chonnam National University, (2010)

[22] Y. S. Park, "Effect of the self-leadership program on the psychological well-being of high school students," Korean Journal of youth studies, vol.20, no.1, 1-24, (2013)

[23] S. H. Jang, S. C. Lee, and S.S. Ham, "The effect of rokaf officer's job satisfaction and psychological wellbeing on their self-leadership," The Korea Contents Society, vol.1, no.3, pp.732-741, (2016)

[24] Y. S Lee, S. H. Pack, and J.G. Kim, "Nursing student self-leadership, self-efficacy, interpersonal relation, college life satisfaction," Journal of the Korea Contents Association, vol.14, no.6, pp.229-240, (2014)

[25] K. T Lee, "The effect of nonverbal communication in university teaching: The moderating role of academic self-efficacy," The Korean Journal of Korean Society for the Study of vocational education, vol.30, no.4, pp.69-87, (2014) 